Development of a Performance-Based Industrial Energy Efficiency Indicator for Corn Refining Plants

Decision and Information Sciences Division

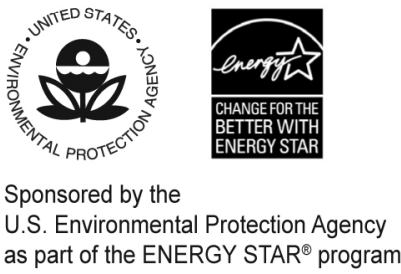




\section{About Argonne National Laboratory}

Argonne is a U.S. Department of Energy laboratory managed by The University of Chicago under contract W-31-109-Eng-38. The Laboratory's main facility is outside Chicago, at 9700 South Cass Avenue, Argonne, Illinois 60439. For information about Argonne, see www.anl.gov.

\section{Availability of This Report}

This report is available, at no cost, at http://www.osti.gov/bridge. It is also available on paper to the U.S. Department of Energy and its contractors, for a processing fee, from:

U.S. Department of Energy

Office of Scientific and Technical Information

P.O. Box 62

Oak Ridge, TN 37831-0062

phone (865) 576-8401

fax (865) 576-5728

reports@adonis.osti.gov

\section{Disclaimer}

This report was prepared as an account of work sponsored by an agency of the United States Government. Neither the United States Government nor any agency thereof, nor The University of Chicago, nor any of their employees or officers, makes any warranty, express or implied, or assumes any legal liability or responsibility for the accuracy, completeness, or usefulness of any information, apparatus, product, or process disclosed, or represents that its use would not infringe privately owned rights. Reference herein to any specific commercial product, process, or service by trade name, trademark, manufacturer, or otherwise, does not necessarily constitute or imply its endorsement, recommendation, or favoring by the United States Government or any agency thereof. The views and opinions of document authors expressed herein do not necessarily state or reflect those of the United States Government or any agency thereof, Argonne National Laboratory, or The University of Chicago. 
ANL/DIS-06-4

\title{
Development of a Performance-Based Industrial Energy Efficiency Indicator for Corn Refining Plants
}

\author{
by \\ G.A. Boyd \\ Decision and Information Sciences Division, Argonne National Laboratory \\ work sponsored by \\ U.S. Environmental Protection Agency \\ Office of Atmospheric Programs \\ July 2006
}





\section{CONTENTS}

ACKNOWLEDGMENTS .............................................................................

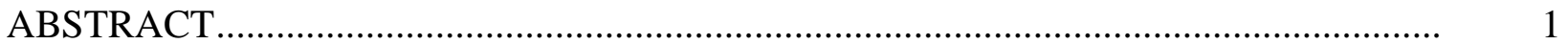

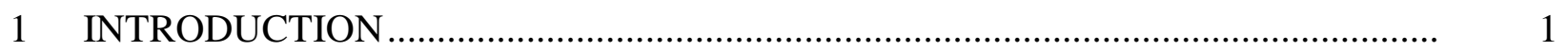

2 BENCHMARKING THE ENERGY EFFICIENCY OF INDUSTRIAL PLANTS ...... 3

2.1 Scope of an Indicator: Experience with the Corn Refining Industry................. 3

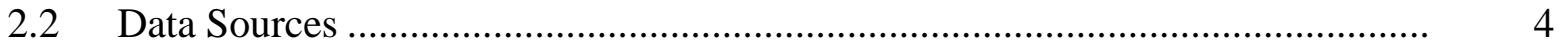

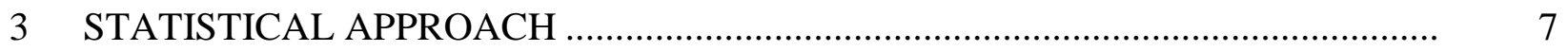

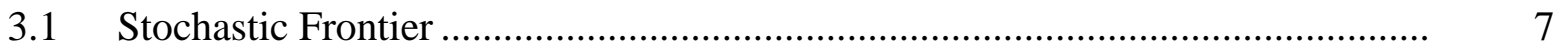

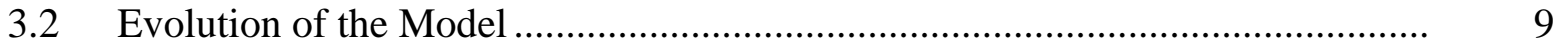

3.3 Model Estimates............................................................................... 10

4 JUDGING THE ENERGY EFFICIENCY OF CORN REFINING PLANTS.............. 13

4.1 How the EPI Works ............................................................................... 13

4.2 Spreadsheet Tool.................................................................................... 14

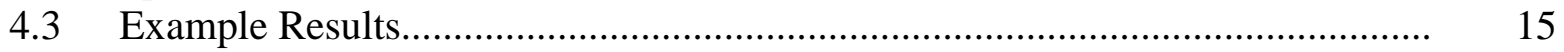

$4.4 \quad$ Use of the ENERGY STAR Corn Refining EPI............................................ 15

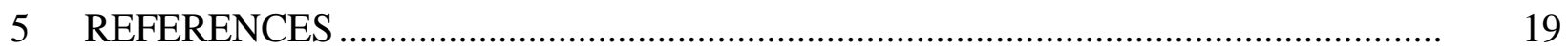

\section{FIGURES}

1 Flow Diagram of the Corn Refining Process .................................................. 5

2 Input Section of the EPI Spreadsheet Tool ....................................................... 16

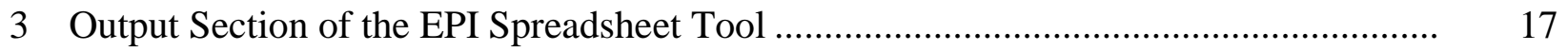

4 Comparison of Hypothetical Corn Refineries That Have the Same Energy Consumption 


\section{TABLES}

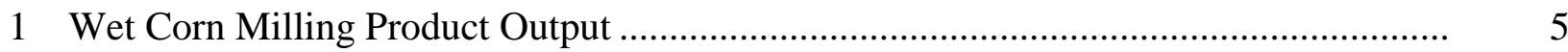

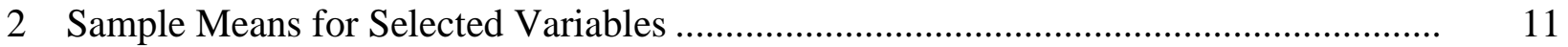

3 Parameter Estimates: Total Primary Energy Frontier in Corn Refining ...................... 12

4 Example Product Mix and Comparison Case Inputs .............................................. 18 


\section{ACKNOWLEDGMENTS}

This work was sponsored by the U.S. Environmental Protection Agency (EPA), Office of Atmospheric Programs. Portions of this report were presented at the Illinois Economics Association's meeting held on October 15-16, 2004, in Chicago, Illinois; the Southern Economic Association's 74th Annual Meeting held on November 21-23, 2004, in New Orleans, Louisiana; and the Institute for Sustainable Energy, Environment, and Economy's invited lecture series held on November 17, 2005, at the University of Calgary, Alberta, Canada. This research also benefited from comments by participants at the Annual ENERGY STAR ${ }^{\circledR}$ Corn Refiners Focus Workshop held in Washington, D.C., on December 11, 2003; in Indianapolis, Indiana, on September 9, 2004; and in Chicago, Illinois, on September 21, 2005.

The research discussed in this report was conducted while the author was a U.S. Bureau of the Census (Census Bureau) research associate at the Chicago Census Research Data Center (RDC). The results and conclusions expressed herein are those of the author and do not necessarily indicate concurrence by the Census Bureau, Argonne National Laboratory, or the EPA. This report was screened to ensure that no confidential data are revealed. Support for this research at the Chicago Census RDC from the National Science Foundation (Awards SES0004335 and ITR-0427889) is gratefully acknowledged. 


\title{
DEVELOPMENT OF A PERFORMANCE-BASED INDUSTRIAL ENERGY EFFICIENCY INDICATOR FOR CORN REFINING PLANTS
}

by

\author{
G.A. Boyd
}

\begin{abstract}
Organizations that implement strategic energy management programs have the potential to achieve sustained energy savings if the programs are carried out properly. A key opportunity for achieving energy savings that plant managers can take is to determine an appropriate level of energy performance by comparing their plant's performance with that of similar plants in the same industry. Manufacturing facilities can set energy efficiency targets by using performancebased indicators. The U.S. Environmental Protection Agency (EPA), through its ENERGY STAR ${ }^{\circledR}$ program, has been developing plant energy performance indicators (EPIs) to encourage a variety of U.S. industries to use energy more efficiently. This report describes work with the corn refining industry to provide a plant-level indicator of energy efficiency for facilities that produce a variety of products - including corn starch, corn oil, animal feed, corn sweeteners, and ethanol — for the paper, food, beverage, and other industries in the United States. Consideration is given to the role that performance-based indicators play in motivating change; the steps needed to develop indicators, including interacting with an industry to secure adequate data for an indicator; and the actual application and use of an indicator when complete. How indicators are employed in the EPA's efforts to encourage industries to voluntarily improve their use of energy is discussed as well. The report describes the data and statistical methods used to construct the EPI for corn refining plants. Individual equations are presented, as are the instructions for using them in an associated Excel spreadsheet.
\end{abstract}

\section{INTRODUCTION}

The ENERGY STAR ${ }^{\circledR}$ program was introduced by the U.S. Environmental Protection Agency (EPA) in 1992 as a voluntary, market-based partnership for reducing air pollution through increased energy efficiency. This government program enables industrial and commercial businesses as well as consumers to make informed decisions that save energy, reduce costs, and protect the environment.

A key step in improving corporate energy efficiency is to institutionalize strategic energy management. The ENERGY STAR guidelines for energy management (EPA 2003), which are 
modeled on the International Organization for Standardization (ISO) quality and environmental standards, identify the components of successful energy management. These include:

- Obtaining the commitment of a senior corporate executive to manage energy across all businesses and facilities operated by the company;

- Appointing a corporate energy director to coordinate and direct the energy program and multidisciplinary energy team;

- Establishing and promoting an energy policy;

- Developing a system for assessing the performance of the energy management efforts, including tracking energy use as well as benchmarking energy in the facilities, operations, and subunits therein;

- Conducting technical assessments and audits to identify areas for improvement;

- Setting goals at the corporate, facility, and subunit levels;

- Establishing an action plan across all operations and facilities, as well as monitoring its successful implementation and promoting the value to all employees;

- $\quad$ Providing rewards for the success of the program; and

- Providing mechanisms for reevaluation and continuous improvement.

Of the major steps taken to develop an energy management program, benchmarking energy use (by comparing current energy performance to that of a similar entity) is critical. In manufacturing, benchmarking may take the form of detailed comparisons of specific production lines or pieces of equipment, or it may be performed at a higher organizational level by gauging the performance of a single manufacturing plant with respect to the industry. Regardless of the application, benchmarking enables companies to determine whether better energy performance can be expected. It empowers them to set goals and evaluate their reasonableness.

This report describes the basic concept of benchmarking and the statistical approach employed, recent experience gained in developing performance-based energy indicators for the corn refining industry, the evolution of the analysis done for this industry, the final results of this analysis, and ongoing efforts by the EPA to improve the energy efficiency of this industry and others. 


\section{BENCHMARKING THE ENERGY EFFICIENCY OF INDUSTRIAL PLANTS}

Among U.S. manufacturers, few industries participate in industrywide plant benchmarking. Both the petroleum and petrochemical industries support plantwide surveys conducted by private companies, and these industries are provided with benchmarks that address energy use and other operational parameters related to their facilities. Most other industries have not benchmarked energy use across their plants. As a result, some energy managers find it difficult to determine how well their plants might perform.

In 2000, the EPA and Argonne National Laboratory discussed a method for developing benchmarks of performance for plant-level energy use within a manufacturing industry. Discussions yielded a plan to use a source of data that would nationally represent manufacturing plants within a particular industry, create a statistical model of energy performance for the industry's plants on the basis of these data and other available sources for the industry, and establish the benchmark on the basis of a comparison of plants implementing best practices, or best-performing plants, to others in the industry. The primary data sources were determined to be the Census of Manufacturing (CM), Annual Survey of Manufactures (ASM), and Manufacturing Energy Consumption Survey (MECS) compiled by the U.S. Bureau of the Census (Census Bureau), supplemented by data provided by trade associations and individual companies on a case-by-case basis.

\subsection{SCOPE OF AN INDICATOR: EXPERIENCE WITH THE CORN REFINING INDUSTRY}

The EPA and Argonne initiated discussions about developing a plant-level benchmark with companies that operate in the corn refining industry, with cooperation from the Corn Refiners Association. Companies with manufacturing plants located in the United States were invited to participate in the discussions. The initial reaction from most companies was supportive yet skeptical about whether a useful benchmark could be developed, largely because of the wide array of products that are produced in this industry from a common set of inputs.

At the outset, the use of the term "plant energy performance indicator" versus "plant benchmark" was discussed with representatives of the industry. Because industry engineers routinely develop benchmarks at many levels of plant operation, including the process-unit level, concern had been expressed that using the word "benchmark" would be confusing and could imply a particular process or tool. For this reason, the EPA chose to use the term ENERGY STAR plant energy performance indicator (EPI).

The EPA and Argonne defined the scope for the EPI. It is a plant-level, not a processspecific, indicator, and it relates plant inputs (in terms of all types of energy use) to plant outputs (as expressed in a unit of production). The EPA relied on a Lawrence Berkeley National Laboratory (LBNL) study of the corn refining industry (Galitsky et al. 2003) to define the energy focus of the model. The LBNL report provides a summary of the primary operations within corn refining plants: steeping, degermination, grinding and screening, starch-gluten separation, 
saccharification, sugar refining, and distillation. Final products may require additional refining or drying steps.

Wet corn milling (Standard Industrial Classification [SIC] code 2046 or North American Industry Classification System [NAICS] code 311221), which is also referred to as corn refining, is a relatively sophisticated process that produces a variety of products for the paper, food, beverage, and other industries. Wet corn milling plants require a large capital investment and are bound by large economies of scale. An average plant in the United States processes at least 100,000 bushels per day (2,500 tonnes per day) and operates continuously for nearly 365 days per year.

The model was designed to account for major, measurable impacts that affect a plant's energy use. The starting point for EPI development was Census Bureau data for industrial plants. For the corn refining industry, these data included information on energy use, total amount of corn processed, and quantities of major products produced at a plant. On the basis of subsequent review comments from the industry, some product categories were disaggregated, and the moisture content of the animal feed product was added to the modeling. The capacity utilization of the plant was included to account for the fixed and variable components of plant operation.

The most important outputs of wet corn milling are corn sweeteners, ethanol, and starch. (The first two are made from the starch in the corn.) Sweeteners fall into three major categories: corn syrup (often called glucose syrup), dextrose, and fructose. Ethanol is an increasingly important component of the U.S. fuel supply. About $60 \%$ of the ethanol produced in the United States currently comes from wet corn milling. ${ }^{1}$ The ethanol is generally produced along with starches and syrups in the refining factories. ${ }^{2}$ Starch is another important corn refining product, with both food and industrial applications, such as in the paper and corrugating industries. Corn oil, produced from the germ component, is another product. Corn refining also produces many by-products that are used in animal feed. Table 1 gives an overview of the output from wet corn milling industries on both a physical output basis and a value basis for the last year of information available. The production process is illustrated in Figure 1.

\subsection{DATA SOURCES}

This analysis uses confidential plant-level data from two sources: the Longitudinal Research Database (LRD) maintained by the Census Bureau's Center for Economic Studies (CES) and Galitsky et al. (2003). The LRD includes nonpublic, plant-level data that are the basis of government-published statistics on manufacturing. The CES constructed a panel of plant-level

1 This percentage is based on value of output. The remaining amount is made mostly through dry corn milling, a similar process that produces ethanol and animal feed by-products but does not produce the other high-value products that wet corn milling produces.

2 The production of ethanol falls under a different industrial classification within the chemicals industry. Wet corn milling falls into SIC 2046 and NAICS 311221. Ethanol production falls into the broad category 2869 (industry organic chemicals, not elsewhere classified) in the SIC system but is separately classified as 325193 (ethyl alcohol) in NAICS. 
TABLE 1 Wet Corn Milling Product Output

\begin{tabular}{lcc}
\hline \multicolumn{1}{c}{ Product } & Tons $\left(10^{6}\right), 2001^{\mathrm{a}}$ & $\$\left(10^{9}\right), 1997^{\mathrm{b}}$ \\
\hline Corn sweeteners & 16.4 & 3.1 \\
Ethanol & Not available & 1.4 \\
Starch & 2.9 & 1.5 \\
Corn oil & 0.6 & 1.0 \\
By-products & 7.2 & 1.6 \\
\hline
\end{tabular}

a These values are from the Corn Refining

Association, reporting on the output from its member companies.

b These values are from the Census Bureau and are reported on the basis of product output, not industry output.

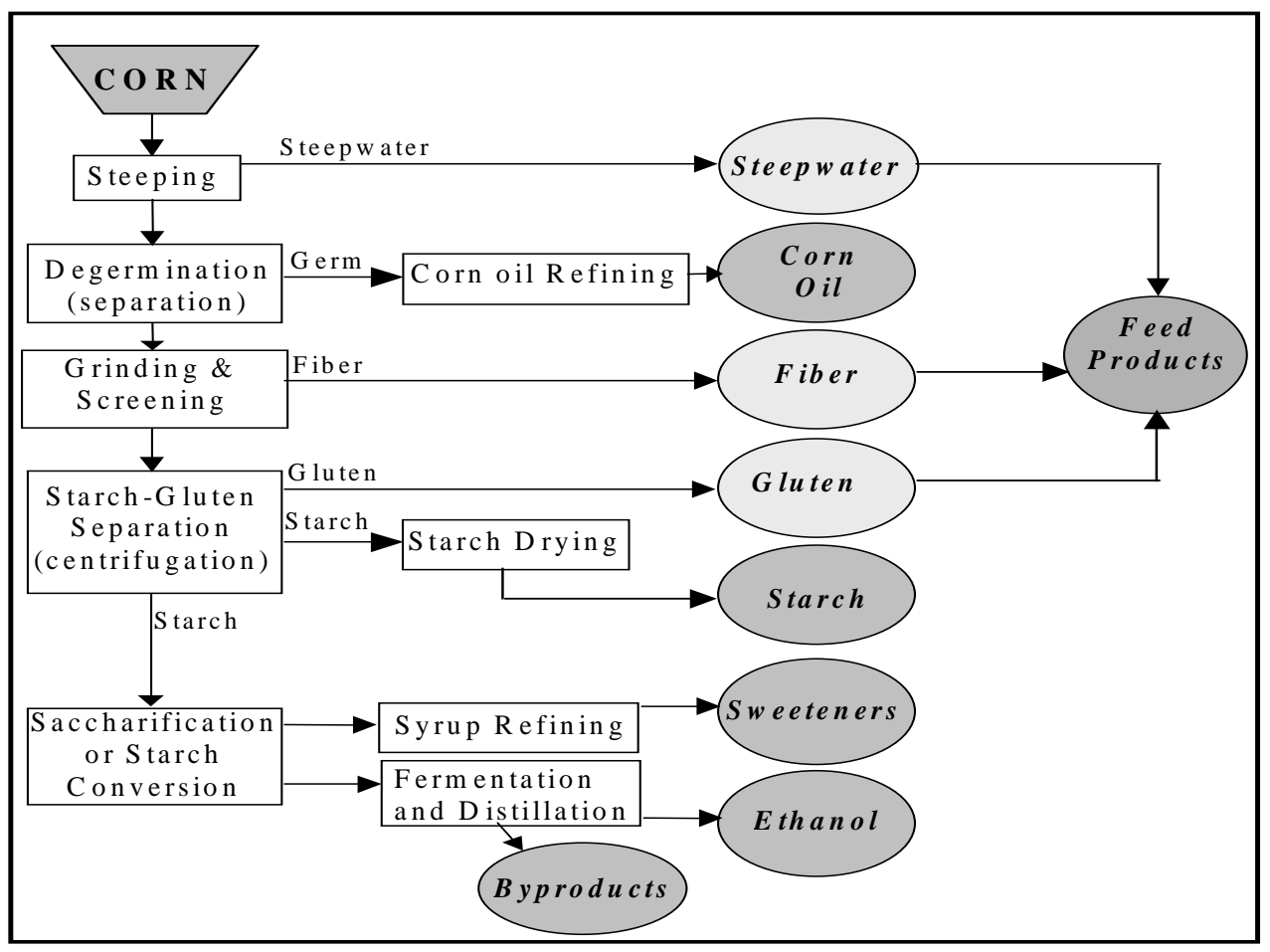

FIGURE 1 Flow Diagram of the Corn Refining Process 
data from the ASM and CM. The LRD covers economic activity (e.g., labor, energy, plant and equipment, costs of materials, and total shipment value of output) for a sample of plants during the survey years, and it provides complete coverage during the years of the economic census.

Under Title 13 of the U.S. Code, these data are confidential. However, CES allows academic and government researchers with special sworn status to access these confidential micro data under its research associate program. The confidentiality restrictions prevent the disclosure of any information that would allow for the identification of a specific plant's or firm's activities. Aggregate figures or statistical coefficients that do not reveal the identity of individual establishments or firms can be released publicly. The use of plant-level data rather than aggregate data significantly enhances the value of the information that can be obtained about economic performance, particularly when the issue of energy efficiency is being examined.

The data were taken from the CMs for 1992 and 1997 for NAICS 311221, which means that plants that produce only ethanol were excluded. Only those plants with capacity estimates that were either identified by Galitsky et al. (2003) or available though private communication and could be matched to the CM data were included in the analysis. Plants that produced products in this NAICS category but did not purchase corn as the primary input were assumed to be germ and corn oil processors and were not included in the analysis. Other plants may have been dropped from the analysis because of irreconcilable discrepancies in the data. The result is that 37 observations (plant years) were included in the analysis. Since 29 plants are identified in Galitsky et al. (one of which is now closed), this number of plant-years in two years of data samples seems fairly representative of this industry.

Product mix was expected to be quite important in this analysis. A list of the product mix in the wet corn milling industry compiled from Census Bureau data follows here: ${ }^{3}$

- Glucose syrup (corn syrup),

- Dextrose (monohydrate and anhydrous),

- High-fructose corn syrup (HFCS),

- Corn starch and dextrin (modified and not modified),

- Corn oils,

- $\quad$ Ethyl alcohol, and

- Gluten feed and meal.

3 The list represents the entire product category list included by the Census Bureau on the economic census forms that companies are required by law to prepare every five years. Other data (not shown) from the Census Bureau is used to develop the EPI. Most plants produce only a subset of these products. The product types shown here are the basis for the production mix adjustments to the EPI. 


\section{STATISTICAL APPROACH}

The goal of this study was to develop an estimate of the distribution of energy efficiency across the industry. Efficiency is the difference between actual energy use and "best practice" energy use (i.e., the lowest energy use achievable). The efficiency that is achievable is influenced by operating conditions, which vary among plants, so the measure of best practice must take these conditions into account. Statistical models are well-suited for accounting for these types of observable conditions but typically focus on average practice, not best practice. However, stochastic frontier regression analysis is a tool that can be used to identify best practice. This section provides the background on the stochastic frontier, a discussion of the review process and the evolution of the model's equations, and the final model estimates.

\subsection{STOCHASTIC FRONTIER}

The concept of the stochastic frontier analysis that supports the EPI can be easily described in terms of the standard linear regression model, which is reviewed in this section. A more detailed discussion on the evolution of the statistical approaches for estimating efficiency can be found in Greene (1993). Consider at first the simple example of a production process that has a fixed energy component and a variable energy component. A simple linear equation for this can be written as

$$
E_{i}=\alpha+\beta y_{i}
$$

where

$$
\begin{aligned}
& E=\text { energy use of plant } i \text { and } \\
& y=\text { production of plant } i .
\end{aligned}
$$

Given data on energy use and production, the parameters $\alpha$ and $\beta$ can be fit via a linear regression model. Since the actual data may not be perfectly measured, and since this simple relationship between energy and production may be only an approximation of the "true" relationship, linear regression estimates of the parameters rely on the proposition that any departures in the plant data from Equation 1 are "random." This implies that the actual relationship, represented by Equation 2, includes a random error term $\varepsilon$ that follows a normal (bell-shaped) distribution with a mean of 0 and variance of $\sigma^{2}$. In other words, about half of the actual values of energy use are less than what Equation 1 would predict, and half are greater.

$$
\begin{gathered}
E_{i}=\alpha+\beta y_{i}+\varepsilon_{i} \\
\varepsilon \sim N\left(0, \sigma^{2}\right)
\end{gathered}
$$


The linear regression gives the average relationship between production and energy use. If the departures from the average (particularly those departures that are above the average) are due to energy inefficiency, we would be interested in a version of Equation 1 that gives the "best" (lowest) observed energy use. The relationship between the lowest energy use at any given level of production can be obtained by shifting the line downward so that all the actual data points are on or above the line. This "corrected" ordinary least squares (COLS) regression is one way to represent the frontier.

While the COLS method is appealing in terms of its simplicity, a more realistic view is that not all the differences between the actual data and the frontier are due to efficiency. Since it is recognized that there may still be errors in data collection and/or reporting, that there may be effects that are unaccounted for in the analysis, and that a linear equation is an approximation of the complex factors that determine manufacturing energy use, we still wish to include the statistical noise (i.e., "random error") term $v_{i}$ in the analysis, but we also want to add a second random component $u_{i}$ to reflect energy inefficiency. ${ }^{4}$ Unlike the statistical noise term, which may be positive or negative, this second error term will follow a one-sided distribution. If the simple example of energy use and production is expanded to include a range of potential effects, we can write a version of the stochastic frontier model as energy use per unit of production as a general function of systematic economic decision variables and external factors:

$$
\begin{gathered}
E_{i}=h\left(X_{i}, Y_{i}, Z_{i} ; \beta\right)+\varepsilon_{i} \\
\varepsilon_{i}=u_{i}-v_{i} \\
v \sim N\left[0, \sigma_{v}^{2}\right],
\end{gathered}
$$

where

$$
\begin{aligned}
& E=\text { energy use, either electricity, nonelectric energy, or total site energy (TSE, } \\
& Y=\text { production, measured by physical production; } \\
& X=\text { systematic economic decision variables (i.e., labor hours worked, materials } \\
& \text { processed, plant capacity, or utilization rates); } \\
& Z \text { = systematic external factors (i.e., heating and cooling loads); and } \\
& \beta=\text { all the parameters to be estimated. }
\end{aligned}
$$

4 "Random" means that this effect is not directly measurable by the analyst but can be represented by a probability distribution. 
It is assumed that energy (in)efficiency $u$ is distributed according to one of several possible onesided statistical distributions ${ }^{5}$ (e.g., gamma, exponential, truncated normal). It is then possible to estimate the parameters of Equation 3, along with the distribution parameters of $u$.

One advantage of the approach is that the parameters used to normalize for systematic effects and describe the distribution of efficiency are jointly estimated. The standard regression model captures the behavior of the average performers, but the frontier regression captures the behavior of the best performers. For example, if the best-performing plants are less sensitive to capacity utilization because they use better shutdown procedures, then the slope representing the estimated relationship between capacity utilization and energy use would not be as steep as the slope for the average plants.

Given data for any plant, Equation 3 can be used to compute the difference between the actual energy use and the predicted frontier energy use:

$$
E_{i}-h\left(X_{i}, Y_{i}, Z_{i} ; \beta\right)+v_{i}=u_{i} .
$$

Since the probability distribution of $u$ has been estimated, Equation 5 represents the probability that the plant inefficiency is greater than this computed difference:

$$
\begin{gathered}
\text { Probability [energy inefficiency } \left.\geq E_{i}-h\left(X_{i}, Y_{i}, Z_{i} ; \beta\right)+v_{i}\right]= \\
1-F\left[E_{i}-h\left(X_{i}, Y_{i}, Z_{i} ; \beta\right)+v_{i}\right] .
\end{gathered}
$$

$F()$ is the cumulative probability density function of the appropriate one-sided density function (e.g., gamma, exponential, truncated normal). The value $1-F()$ in Equation 5 defines the EPI score and may be interpreted as a percentile ranking of the energy efficiency of the plant. In practice, we can measure only $E_{i}-h\left(X_{i}, Y_{i}, Z_{i} ; \beta\right)=u_{i}-v_{i}$, so this implies that the EPI score $1-F\left[E_{i}-h\left(X_{i}, Y_{i}, Z_{i} ; \beta\right)\right]=1-F\left(u_{i}-v_{i}\right)$ is affected by the random component of $v_{i}$; that is, the score will reflect the random influences that are not accounted for by the function $h(*)$. Since this ranking is based on the distribution of inefficiency for the entire industry but normalized to the specific systematic factors of the given plant, this statistical model allows the user to answer the hypothetical but very practical question, "How does my plant compare to everyone else's in my industry, if all other plants were similar to mine?"

\subsection{EVOLUTION OF THE MODEL}

The model evolved over a period of time on the basis of comments from industry reviewers and subsequent analyses. Industry participants tested each version of the model. Companies were asked to input actual data on all of their plants and to then determine whether the results were consistent with any energy efficiency assessments that might have been made for these plants. The resulting comments were considered in order to improve the EPI.

5 We also assume that the two types of errors are uncorrelated: $\sigma_{u, v}=0$. 
A variety of specifications, including various aggregations and disaggregations of the product categories, were initially tried. The initially preferred model was cleared by the Census Bureau for release to the industry review process. At first the comments focused on product specification. At the request of industry participants, we disaggregated the monohydrate and anhydrous dextrose from the other categories of sweeteners. This product is a very high-grade sugar that requires substantial processing. We also examined data on the sugar content of highfructose corn syrup (HFCS). Census Bureau data divides HFCS sugar content into three broad categories. The disaggregation of monohydrate and anhydrous dextrose from other types of sugar substantially improved the model, while the addition of the sugar content of HFCS did not. We suspect that the quality of the data for the HFCS categories was responsible. We also tested whether location-driven differences in climate, in the form of heating degree days (HDDs), would have an impact on energy use. They did not.

In subsequent comments, the issue of gluten feed was raised. Gluten feed is one product produced by corn refining. This byproduct of the initial milling and separation is sold as animal feed. The industry typically dries the gluten feed for shipment, but plants that are close to agricultural markets may ship some of the product in wet form. Companies voluntarily provided data on the moisture content of their shipments of gluten feed. Specifically, they provided data on the dry solids content. By taking the ratio of dry solids to the "commercial basis" as reported to the Census Bureau, we constructed a moisture variable. This variable was significant, and including it improved the standard errors of the other variables in the model.

\subsection{MODEL ESTIMATES}

For simplicity, we assume that the function $h()$ is linear in the parameters but allow for nonlinear transformations of the variables. In particular, we found that nonlinear (quadratic) terms in some of the variables were appropriate. Several alternatives for the distribution of the inefficiency term $u$ were tried. The distribution that performed best was half normal:

$$
\begin{aligned}
E_{i}= & \beta_{0}+\beta_{1} \text { Corn }+\beta_{2} Y_{\text {Modified Starch }}+\beta_{3} Y_{\text {MA Glu cose }}+\beta_{4} Y_{\text {Glucose }}+\beta_{5} Y_{\text {Alcohol }} \\
& +\beta_{6} \frac{\text { Corn }}{\text { Capacity }}+\beta_{7}\left(\frac{\text { Corn }}{\text { Capacity }}\right)^{2}+\beta_{8}(\text { Moisture })+u_{i}-v_{i} .
\end{aligned}
$$

The variables included in $h(*)$ are as follows:

$$
\begin{aligned}
\text { Corn } & =\text { total amount of corn processed in a year }\left(10^{9} \mathrm{lb}\right), \\
Y_{\text {Modified Starch }} & =\text { total amount of modified starch produced in a year }\left(10^{9} \mathrm{lb}\right), \\
Y_{\text {MAGlucose }} & =\text { total amount of monohydrate and anhydrous dextrose }\left(10^{9} \mathrm{lb}\right), \\
Y_{\text {Glucose }} & =\text { total amount of glucose syrup sweeteners and solids }\left(10^{9} \mathrm{lb}\right),
\end{aligned}
$$




$$
\begin{aligned}
Y_{\text {Alcohol }} & =\text { total amount of alcohol }\left(10^{9} \mathrm{gal}\right) \\
\text { Moisture } & =\text { one minus the } \% \text { moisture content of gluten feed }, \\
\text { Capacity } & =\text { plant capacity (annual capacity of corn processed }), \text { and } \\
E & =\text { total primary energy (defined above })\left(10^{12} \mathrm{Btu}\right) .
\end{aligned}
$$

The sample means for selected variables are shown in Table 2. Confidentiality restrictions prevent disclosure of the means for production mix variables, but the total value of shipments is shown in the table.

The estimated coefficients of $h(*)$ are given in Table 3 . The last two variables in Table 2 are the standard deviation of the random error term $v$ and the standard deviation of the inefficiency term $u$, which is assumed to be normally distributed and truncated at zero. All the coefficients are estimated with a high degree of confidence.

The major effects in the corn refining model are total corn processed, the mix of products, and capacity utilization. Nonmodified starch and HFCS are not included in the equation but are represented implicitly. Since there is a mass balance relationship between the amount of corn processed and the final products, we can interpret all of the production variables relative to a plant producing either of these two products. For example, the positive coefficients for modified starch, alcohol, and anhydrous dextrose imply higher energy requirements for a given level of corn processed into either starch or HFCS, while the negative coefficient for glucose sweeteners implies relatively lower energy requirements. Gluten products were excluded from the model since all plants produce them in quantities that are nearly proportional to the amount of corn processed (i.e., they are direct by-products).

TABLE 2 Sample Means for Selected Variables

\begin{tabular}{ll}
\hline & \multicolumn{1}{c}{ Variable Mean } \\
\hline & \\
2.644 & $\mathrm{X}$ \\
7.506 & $\mathrm{E}$ \\
5.327 & $\mathrm{E}$ (from fuels) \\
2.014 & E (from electricity) \\
0.757 & CU \\
289.9 & Total value of shipments $\left(10^{6} \$\right)$ \\
\hline
\end{tabular}


TABLE 3 Parameter Estimates: Total Primary Energy Frontier in Corn Refining

\begin{tabular}{lrrr}
\hline \multicolumn{1}{c}{ Parameter } & Coefficient & Standard Error & z-test \\
\hline & & & \\
Constant & 2.78 & 0.0008 & $3,275.1$ \\
Corn & 2.90 & 0.0001 & $24,568.1$ \\
Modified starch & 2.12 & 0.0003 & $6,551.4$ \\
Dextrose (monohydrate and anhydrous) & 4.48 & 0.0006 & $7,943.8$ \\
Glucose & -0.51 & 0.0001 & $-4,622.9$ \\
Alcohol & 16.12 & 0.0005 & $32,559.1$ \\
Utilization & -11.50 & 0.0022 & $-5,203.5$ \\
Utilization squared & 5.37 & 0.0014 & $3,899.0$ \\
Moisture content $(\%)$ & 0.03 & 0.0005 & 66.0 \\
$\sigma_{v}$ & -30.77 & 178.67 & -0.17 \\
$\sigma_{u}$ (truncated normal) & 1.50 & 0.23 & 6.44 \\
\hline
\end{tabular}




\section{JUDGING THE ENERGY EFFICIENCY OF CORN REFINING PLANTS}

\subsection{HOW THE EPI WORKS}

The corn refining EPI scores the energy efficiency of a plant based in the United States. To use the tool, the following information must be available for a plant:

\section{Energy purchases}

Data are needed by type of energy (e.g., electricity or fuel) for the current year and a baseline year defined by the user.

- Electricity: Data for electricity should include only total electricity purchased or transferred into the plant from another facility. Units should be supplied in terms of site energy (i.e., in kilowatt-hours or million Btu on the basis of 3,412 Btu per $1 \mathrm{kWh}$ ). When total primary energy is calculated, electricity is converted on the basis of $10,236 \mathrm{Btu}$ per $1 \mathrm{kWh}$, or, alternatively, 1 Btu of electric energy (site) $=3$ Btu of electric energy (primary). Note: If compressed air is transferred in from another facility or central utility in the plant, then that consumption should be converted back to kilowatt-hours by using plant average conversion efficiencies.

- Nonelectric energy use: All other forms of energy should be included. When total primary energy is calculated, $1 \mathrm{Btu}$ of nonelectric energy (site) $=1 \mathrm{Btu}$ of nonelectric energy (primary). Note: If steam is transferred in from another facility or central utility in the plant, then the consumption should be converted back to Btu by using plant average boiler conversion efficiencies.

- Energy costs: The information on energy costs can be input by the user. These costs do not affect the EPI score. They are included in the spreadsheet when the EPI is used as a management tool.

2. Plant location zip code

Zip codes are used to determine default values for state-level average energy prices.

\section{Total amount of corn processed during the year}

4. Amount of corn processed per day

The annual capacity is defined on the basis of the assumption that there are 360 days of operation per year. 
5. Total amount and type of products produced during the year (commercial basis)

The products are as follows:

- HFCS,

- Crystalline and anhydrous glucose,

- Other (non-HFCS) sweeteners,

- Modified starch,

- Nonmodified starch, and

- Total alcohol.

\section{Moisture content of the gluten feed}

On the basis of these data inputs, the EPI will report a score for the plant in the current time period and the baseline time period that reflects the relative energy efficiency of the plant compared to that of the industry. It is a percentile score on a scale of 0 to 100. For a current plant, the tool also computes the values for an "efficient" plant. Plants that score 75 or better are classified as efficient. (ENERGY STAR defines the 75th percentile as efficient.) A score of 75 means a particular plant is performing better than $75 \%$ of the plants in the industry.

The model also reports on the average plant in the industry (defined as the 50th percentile). Aside from scoring, an industrial user can determine the energy output ratio (million Btu/bushel) and an annual energy cost (dollars per year) for a plant, calculated from national cost figures for the current and baseline years (or user-input actual costs). The projected energy costs for the average and efficient plants are also computed on the basis of the assumption that the efficiency changes are evenly distributed across energy types. Although the underlying model was developed from actual data for U.S.-based plants, the tool does not contain or reveal any confidential information.

\subsection{SPREADSHEET TOOL}

To facilitate the review and use of data by industry energy managers, a spreadsheet was constructed to display the results of the EPI for a set of plant-level inputs. The spreadsheet accepts the raw plant-level inputs described above, computes the values for $h($ ), and then displays the results from the truncated distribution function for the total primary energy models presented in Equation 6. The results are based on user-input values for the basic model input described above. By graphically displaying the results, the spreadsheet helps energy managers compare the magnitude of the systematic effects attributable to changes in those inputs on the efficiency distribution. The energy managers were encouraged to input data for their own plants and then provide comments.

During the review process, a possible bias against small plants was noted. The spreadsheet was revised to compute the percentile scores by comparing all plants to a reference plant of average size. This is done by computing the ratio of a 170,000-bushel-per-day plant to the actual plant capacity that is input by the user. This ratio is applied to all energy and production values. The percentile scores are computed, then the implied energy uses for the 
50th-percentile plants and that for the 75th-percentile plants are scaled back to be consistent with the user-input plant capacity.

A version of this spreadsheet dated June 1, 2006, which corresponds to the results described in this report, is available from the ENERGY STAR Web site at http://www.energystar.gov/industry. An example of the input section of the spreadsheet is shown in Figure 2. The results section is shown in Figure 3.

\subsection{EXAMPLE RESULTS}

To illustrate how the product mix affects the frontier and a plant's relative efficiency, a hypothetical plant is constructed. The product mix shown in Table 4 is not for a specific plant, and it is not based on the sample means, but it is consistent on a mass balance basis with the amount of corn processed. In this comparison case, nonmodified starch production is shifted to modified starch production, which shifts the frontier. A plant with the same level of energy use would have lower levels of inefficiency and a higher percentile ranking on the basis of the estimated variance of the truncated normal efficiency term. The truncated normal cumulative distribution functions are plotted relative to the predicted values from the frontier for the two hypothetical plants in Figure 4.

\subsection{USE OF THE ENERGY STAR CORN REFINING EPI}

After three years of work with corn refining plants, the ENERGY STAR corn refining EPI is complete, as is a spreadsheet tool for calculating EPI scores. The EPA intends to use this EPI to motivate improvement in energy efficiency in U.S.-based corn refining plants. The EPA, through its ENERGY STAR program that focuses on energy efficiency in corn refining, has been working closely with the companies that make up in this industry to promote strategic energy management. The EPI is an important tool that enables companies to determine how efficiently each plant is using energy and whether better energy performance should be expected.

The EPA recommends that companies use the EPI on a regular basis. At a minimum, it suggests that corporate energy managers benchmark each plant once a year. A more proactive plan would be to use benchmarks for every plant in the company on a quarterly basis. The EPA suggests that the EPI scoring be used to set goals for improving energy efficiency at both the plant and corporate levels.

The model described in this report is based on the performance of the industry for a specific period of time. Since it is likely that overall energy efficiency will change as technology and business practices change, this model will need to be updated. The EPA therefore plans to update the model every few years, contingent on whether newer data are made available by the industry. 


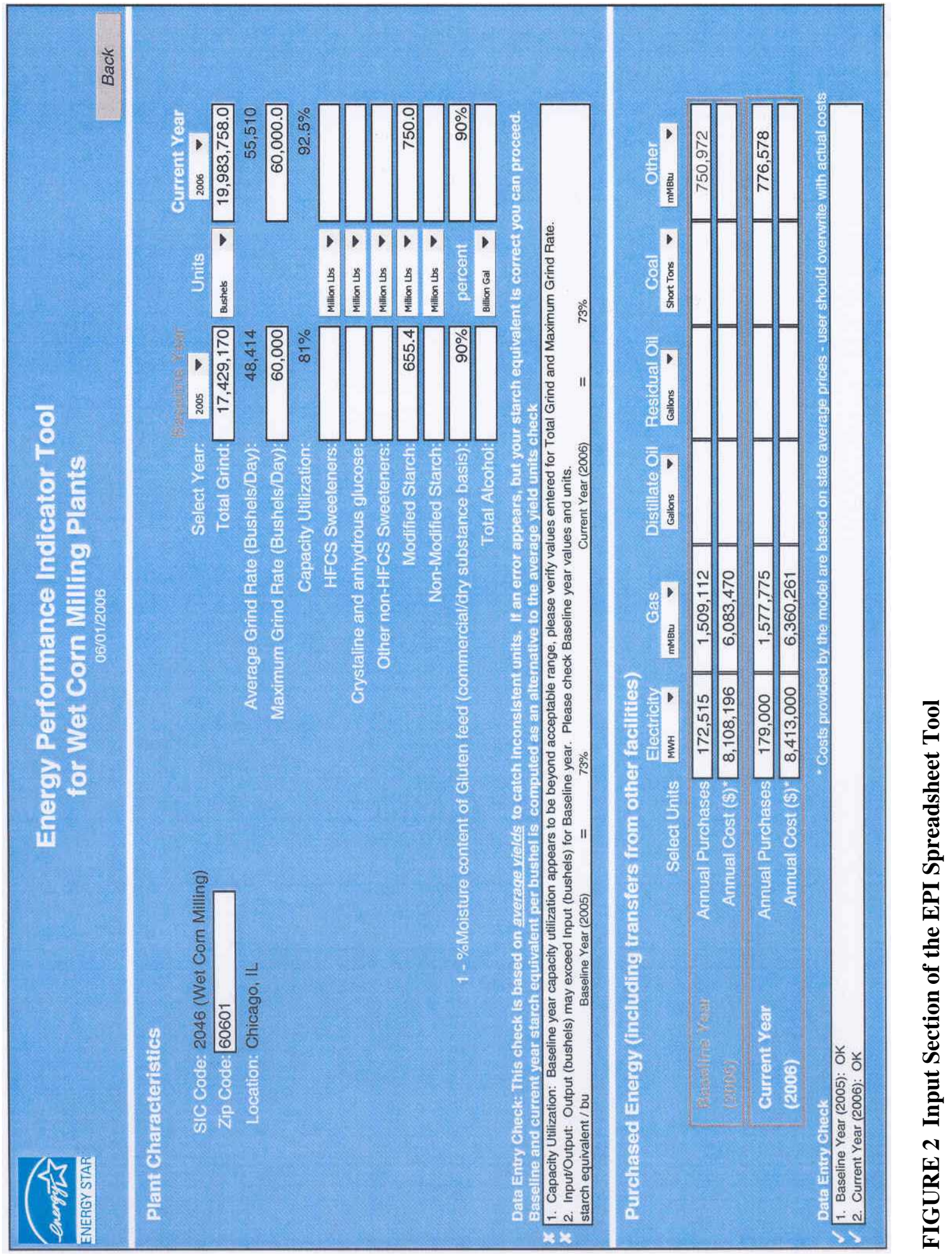




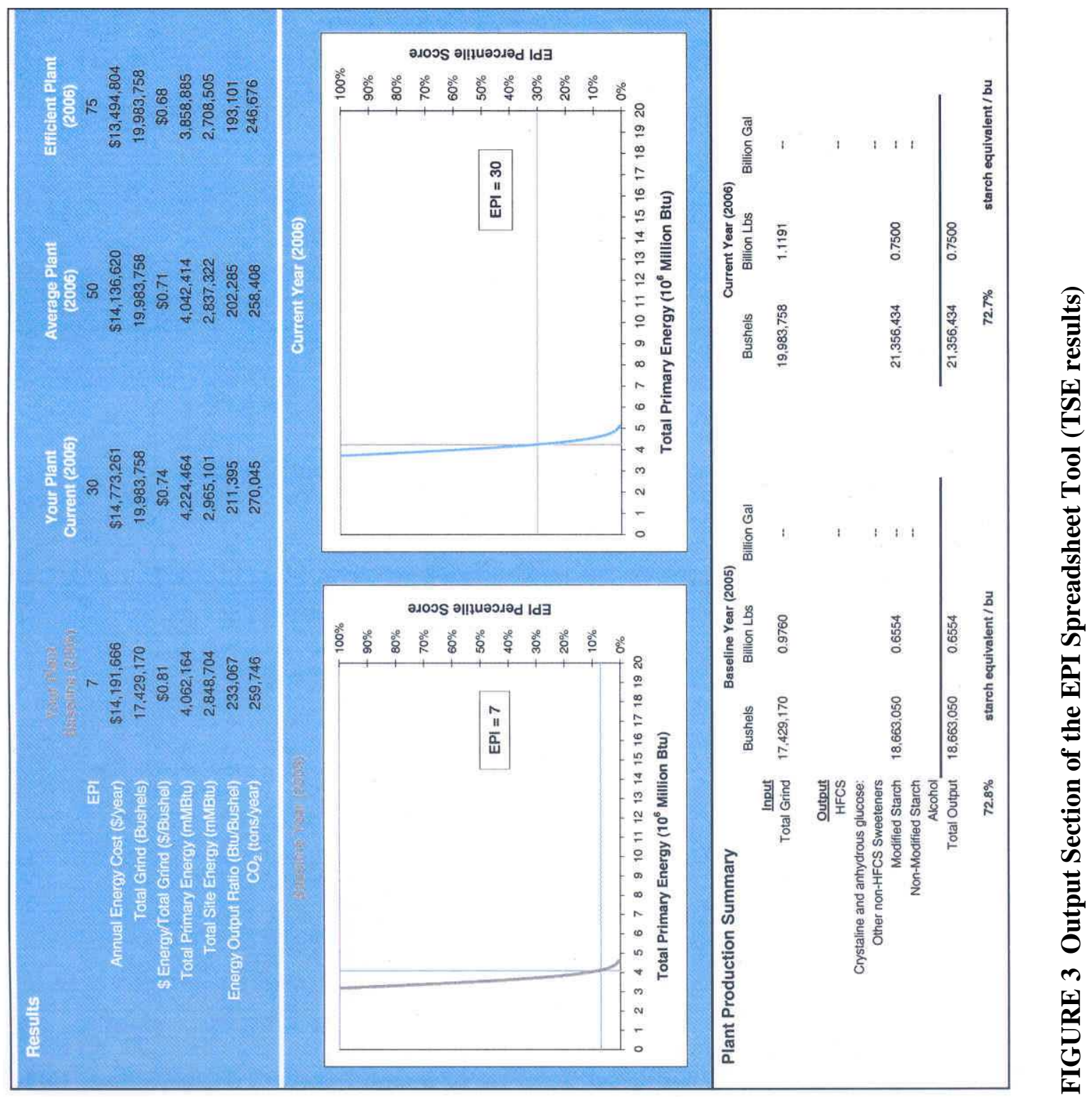


TABLE 4 Example Product Mix and Comparison Case Inputs

\begin{tabular}{lcc}
\hline \multicolumn{1}{c}{ Parameter } & Baseline & Comparison Case 1 \\
\hline Total grind $\left(10^{6} \mathrm{lb}\right)$ & $2,644.50$ & $2,644.50$ \\
Average grind rate (bushels/d) & $131,176.00$ & $131,176.00$ \\
Maximum grind rate (bushels/d) & $131,176.00$ & $131,176.00$ \\
Capacity utilization $(\%)$ & 100 & 100 \\
HFCS sweeteners $\left(10^{6} \mathrm{lb}\right)$ & 300 & 300 \\
Crystalline and anhydrous glucose $\left(10^{6} \mathrm{lb}\right)$ & 0 & 0 \\
Other non-HFCS sweeteners $\left(10^{6} \mathrm{lb}\right)$ & 500 & 500 \\
Modified starch $\left(10^{6} \mathrm{lb}\right)$ & 743.8 & 943.8 \\
Nonmodified starch $\left(10^{6} \mathrm{lb}\right)$ & 200 & 0 \\
Total alcohol $\left(10^{6} \mathrm{gal}\right)$ & 0 & 0 \\
\hline
\end{tabular}

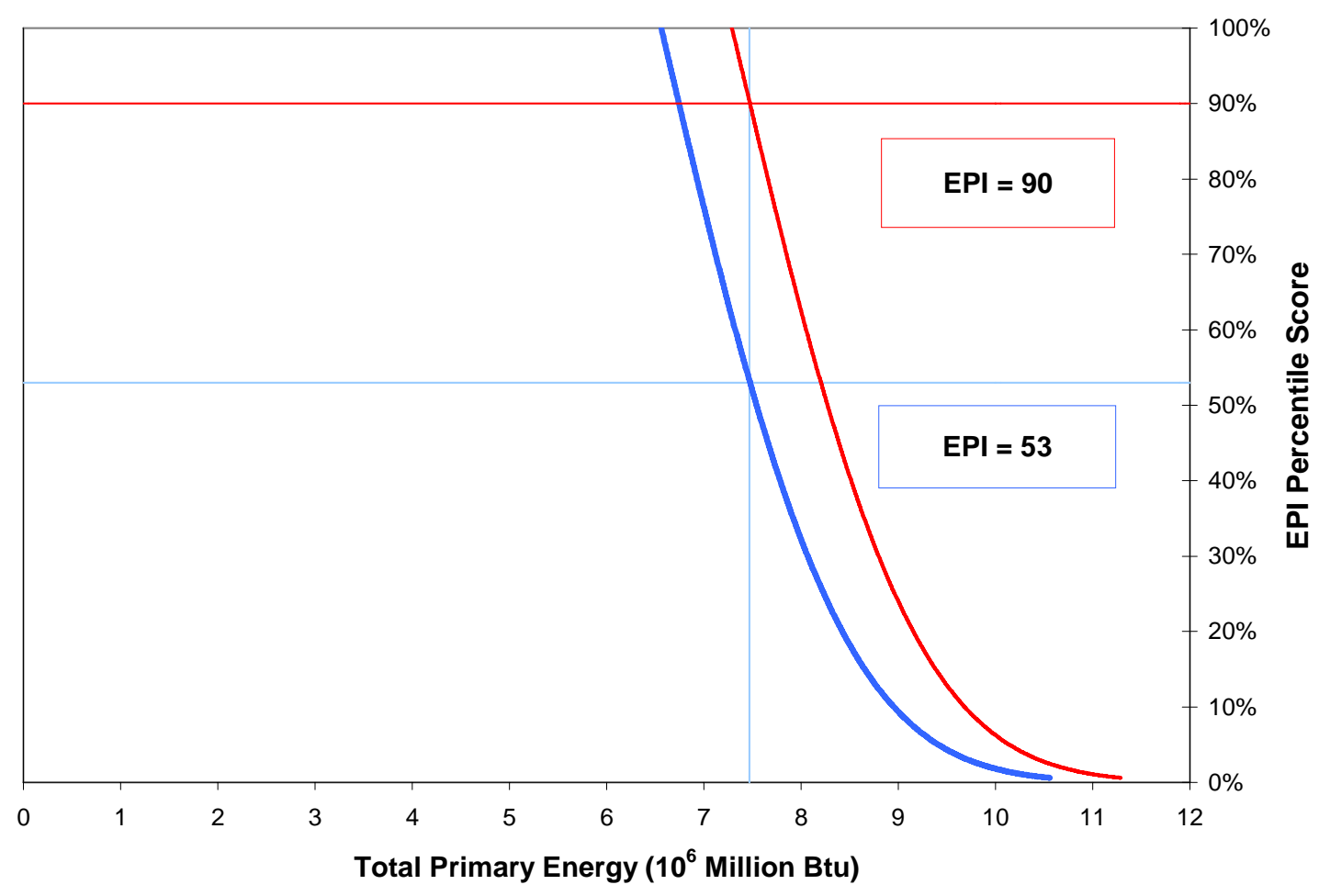

FIGURE 4 Comparison of Hypothetical Corn Refineries That Have the Same Energy Consumption 


\section{REFERENCES}

EPA (U.S. Environmental Protection Agency), 2003, Guidelines for Energy Management, Washington, DC; http://www.energystar.gov/index.cfm?c=guidelines.guidelines_index.

Galitsky, C., et al., 2003, "Energy Efficiency Improvement and Cost Saving Opportunities for the Corn Wet Milling Industry: An ENERGY STAR Guide for Energy and Plant Managers," Paper LBNL-52307, Lawrence Berkeley National Laboratory, Berkeley, CA, July 1;

http://repositories.cdlib.org/lbnl/LBNL-52307.

Greene, W.H., 1993, “The Econometric Approach to Efficiency Analysis,” pp. 68-119 in The Measurement of Productive Efficiency: Techniques and Applications, H. Fried et al. (editors), Oxford University Press, NY. 



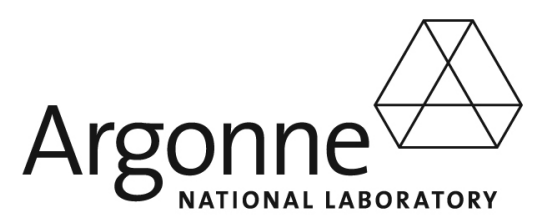

Decision and Information Sciences Division

Argonne National Laboratory

9700 South Cass Avenue, Bldg. 900

Argonne, IL 60439-4832

www.anl.gov

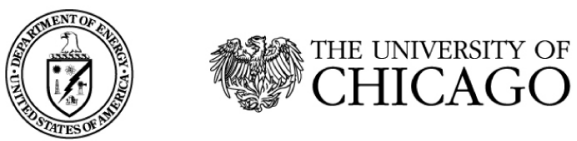

A U.S. Department of Energy laboratory managed by The University of Chicago 